\title{
O processo de formação de Comissões de Saúde do trabalhador da educação: experiência e política
}

The Health Committee formation process of the education workers: experience and policy

http://dx.doi.org/10.5007/2178-4582.2016v50n2p334

Suzana Maria Gotardo

Hervacy Brito

Maria Carolina de Andrade Freitas

Maria Elizabeth Barros de Barros

Vânia Carvalho de Araújo

Universidade Federal do Espírito Santo, Vitória/ES, Brasil

\begin{abstract}
O presente artigo visa problematizar a prática de formação empreendida em Projeto Piloto de Comissões de Saúde do Trabalhador da Educação (COSATEs) no município de Serra/ES. Tais Comissões se organizam como efeito de uma mobilização para a implementação de uma política pública que efetive ações de produção de saúde nas escolas do referido município. Nesse sentido, articula experimentações deste campo com conceitos oriundos de obras de Hannah Arendt, Walter Benjamin e Giorgio Agamben, tais como: Experiência, Ação Política, Dispositivo, Profanação e Amizade. Tal exercício contribui para sustentar a análise dos efeitos produzidos no percurso experimentado, tendo em vista a indagação de como fomentar uma política pública por meio de uma estratégia formativa.
\end{abstract}

Palavras-chave: saúde do trabalhador; educação; política; experiência; formação.
This article aims to discuss the formation practice undertaken in a Health Committee Pilot Project for education workers (COSATE) in Serra/Espirito Santo. These committees are the result of an organized mobilization for a public policy implementation that performs health production actions in the schools of the municipality. In this sense, this work tries to articulate this field experience with some theoretical concepts of Hannah Arendt, Walter Benjamin and Giorgio Agamben works, such as: Experience, Political Action, Device, Profanation and Friendship. Such exercise helps us to support the analysis of the produced effects in the experienced journey, considering the question of how to promote the public policy by means of a formation strategy.

Keywords: worker health; education; policy; experience; formation.

\section{As comissões de saúde do trabalhador da educação (COSATEs) em Serra/ES}

Permitir-nos-ia o estudo da experiência, como categoria conceitual, entrecruzar a noção de política, no sentido arendtiano - ou seja, como um agir que indica um meio de compartilhar as questões da vida comum (ALMEIDA, 2011; ARENDT, 2009; CARVALHO, 2013) - a uma kairologia, ou, a afirmação de um tempo oportuno, um tempo messiânico, e à noção de profanação, trazidas por Agamben, a partir de seus estudos sobre Benjamin? (AGAM- 
BEN, 2005; 2007). E em que tal exercício de pensamento auxiliar-nos-ia a dimensionar e problematizar nossa prática de pesquisa com trabalhadores da educação?

As indagações que se colocam são fruto de um exercício de análise acerca do processo formativo que vem sendo realizado com as primeiras Comissões de Saúde do Trabalhador da Educação (COSATEs) no município de Serra/ES. Estas funcionaram durante o ano de 2014 como um projeto piloto que visou investigar a viabilidade de tais comissões serem institucionalizadas no âmbito da administração municipal. Surgem como produto das atividades do Fórum COSATE $^{1}$, o qual congrega diversos segmentos envolvidos com a rede municipal de Educação Básica de Serra/ES, que entendem ser a saúde do trabalhador um ponto imprescindível na discussão acerca da qualidade da educação pública (ZAMBONI; SZPILMAN; MIRANDA; BARROS, 2013).

Cabe destacar a importância dessa proposta, tendo em vista que, dentre os vários campos da atividade humana, a educação configura-se como um meio problemático no que tange aos processos de adoecimento relacionados ao trabalho. No caso do município de Serra/ES, pesquisadores do Programa de Formação e Investigação em Saúde e Trabalho da Universidade Federal do Espírito Santo (PFIST/UFES), após pesquisa realizada com 289 professores de 22 escolas, constataram que o problema assume proporções preocupantes, as quais, inclusive, relacionam-se a um alto índice de licenças médicas e processos de readaptação funcional. Tendo isso em vista, a aposta do Fórum é que a implementação de tais Comissões pode produzir uma modificação importante nessas circunstâncias, por meio do princípio de que o trabalhador é também gestor e um agente fundamental no conhecimento e análise das atividades que realiza (SOUZA; ALOQUIO; FILHO; CHIABAI; LUCIANO; BROTTO, 2011).

Nesse sentido, a prática das COSATEs em Serra/ES, pautada em pressupostos das Clinicas do Trabalho, requer que façamos da pesquisa um processo de análise e transformação do trabalho em educação. Seguindo as pistas dessas clínicas, não se perspectiva explicitar algo de individual no trabalha-

\footnotetext{
1 O Fórum COSATE constituiu-se em agosto de 2012 com o objetivo de implementar as Comissões de Saúde do Trabalhador da Educação no município de Serra-ES, a partir da articulação de várias instituições, a saber: Programa de Formação e Investigação em Saúde e Trabalho da Universidade Federal do Espírito Santo (PFIST-UFES), Centro de Referência em Saúde do Trabalhador do Espírito Santo (CEREST-ES), Ministério Público do Espírito Santo (MP-ES), Sindicato dos Trabalhadores em Educação Pública do Espírito Santo (SINDIUPES), Conselho Municipal de Educação do município de Serra, Fundação Jorge Duprat e Figueiredo (FUNDACENTRO), Divisão de Medicina e Segurança do Trabalho da Prefeitura Municipal de Serra (DMST-Serra), profissionais de escolas municipais de Serra e de outros órgãos vinculados à Secretaria Municipal de Educação de Serra (SEDU-Serra). Desde então o Fórum tem se reunido mensalmente, sendo que os encontros são marcados por uma lógica baseada no diálogo e na autogestão, por meio da qual a pauta e os encaminhamentos são produzidos pelos presentes, tendo em vista contribuir para a promoção de saúde no ambiente escolar.
} 
dor, mas sustentar o diálogo que pode trazer à visibilidade o coletivo que nos constitui e a interação entre as duas atividades, a de pesquisar e aquela a ser pesquisada.

Assim, o trabalho com as COSATEs efetiva-se na medida em que os educadores engajam-se na análise das situações laborais em sua concretude, produzindo problemas, imprimindo deslocamentos em condições instituídas. É por meio de diálogo que as análises promovem uma inflexão no modo como o próprio trabalhador apreende a organização do seu trabalho, numa direção do que seria um "construtivismo radical" (CLOT, 2008).

Considerando, como já mencionado, os altos índices de adoecimento referidos ao trabalho em educação, cabe ainda ressaltar que, na ótica das Clínicas do Trabalho, a compreensão dos mesmos não deve pautar-se numa unicidade causal, nem numa perspectiva médica biologizante. É preciso trazer às discussões a multidimensionalidade da produção desse adoecimento no trabalho (organização, condições, carga, jornada, política educacional, entre outros). $\mathrm{O}$ trabalho não pode ser analisado de maneira isolada, tendo em vista a interação de vários fatores no exercício dessa atividade ${ }^{2}$, que muitas vezes pode gerar fadiga, riscos, sofrimento. Assim sendo, acreditamos na importância de estabelecer estratégias coletivas de enfrentamento quanto aos problemas levantados pelos trabalhadores. Esse tem sido o exercício constante nas práticas do Fórum COSATE e do projeto piloto disparado pelo mesmo.

$\mathrm{O}$ que ora designamos por projeto piloto refere-se a uma ação realizada no período de setembro a dezembro de 2014 e foi possibilitado pela autorização da Secretaria Municipal de Educação de Serra (SEDU/Serra), a qual oportunizou disponibilidade de carga horária de quatro horas semanais aos profissionais que compõem tais COSATEs para o desenvolvimento de atividades ligadas às mesmas. Participaram do projeto piloto duas escolas: um Centro Municipal de Educação Infantil (CMEI) e uma Escola Municipal de Ensino Fundamental (EMEF), ambas escolhidas em processo de intensa discussão promovido pelo Fórum COSATE ${ }^{3}$. Em cada uma das escolas, por sua vez, foram disparados debates para a eleição dos membros que integraram esse projeto. Os membros então eleitos participaram de curso de formação, o qual se propôs subsidiar o trabalho nas Comissões. Cabe destacar que o formato "curso" foi tomado como um disparador para aquecer um processo formativo ampliado. A ideia de disparador indica que tal ação pode se desdobrar em distintas direções e comportar desequilíbrios e tensões, bem como oportuni-

\footnotetext{
2 Entendemos atividade como "a forma como os trabalhadores se engajam, a partir dos meios de que dispõem ou inventando outros, na gestão dos objetivos do trabalho" (BOTECHIA; ATHAYDE, 2008).

3 Durante o ano de 2015 tal organização da jornada de trabalho não pôde ser pactuada com a SEDU/Serra. O trabalho das COSATEs nas escolas mencionadas, entretanto, não cessou, mas tem acontecido com mais dificuldades, mediante arranjos internos tecidos pelos próprios trabalhadores.
} 
dades, mudanças e derivações que extrapolam o próprio formato do curso tal como planejado.

O "curso" de formação foi elaborado por uma comissão do Fórum COSATE e empreendido sob a coordenação de pesquisadores vinculados ao PFIST/ UFES, constituindo-se ainda como uma estratégia de pesquisa-intervenção. Conforme Aguiar e Rocha (2007), esta refere-se a um tipo de pesquisa-participativa que se destaca pela abordagem micropolítica ${ }^{4}$ dos processos em estudo. Parte do entendimento que pesquisador e campo estão em processo de coengendramento, atravessados por linhas de forças que precisam ser colocadas em análise. Assim, o conhecimento produzido por meio da interferência da pesquisa não é tomado pelo princípio da dicotomia falso-verdadeiro, mas a partir de regimes de produção de verdade, efeitos de relações de resistência e poder, conforme nos impele a pensar Foucault (2008). Parte-se, então, da noção de que "[...] o conhecimento enquanto produção e o sujeito inscrito nesse processo se fazem em condições determinadas, o que torna imprópria qualquer alusão acerca de uma possível neutralidade que nortearia as práticas em pesquisa" (AGUIAR; ROCHA, 2007, p. 650).

Tendo isso em vista, a experiência formativa propiciada pelo projeto piloto foi pautada no princípio de formação no e pelo trabalho, contemplando atividades de encontros presenciais e atividades de dispersão, a serem desenvolvidas nos locais de trabalho.

Nas atividades de encontros presenciais reuniram-se os membros das duas COSATEs piloto, juntamente à equipe responsável pela formação. Foi priorizada, nesse espaço, uma dinâmica dialógica, conforme nos indicam as Clínicas do Trabalho (CLOT, 2006; SCHWARTZ; DURRIVE, 2007), na qual: os participantes traziam as experiências de seu trabalho, eram apresentados a conteúdos conceituais e posteriormente analisavam a própria produção do conhecimento.

Nas atividades de dispersão, os participantes discutiam entre si e/ou com a comunidade escolar temas e atividades previamente programados, de modo a articular elementos abordados nos encontros presenciais com o cotidiano de trabalho, atuando ainda como multiplicadores ${ }^{5}$ das questões trabalhadas na formação.

$4 \quad$ Micro e macropolítica não são aqui expressões que remetem a dimensões: pequeno ou grande. Tais concepções referem-se a um plano de visibilidade. Macro, nesse sentido, remete ao plano das formas, do que está instituído e, portanto, facilmente identificado; fazem parte do que Guattari e Rolnik (2007) designam por nível molar. Já a micropolítica é uma referência ao plano das intensidades, molecular, ao campo de forças, agenciamentos e embates que vão modificando a realidade.

5 Ao dizermos que os membros das COSATEs atuam como multiplicadores, nos remetemos à ampliação dos temas, análises e discussões empreendidos no curso de formação para a comunidade escolar. Desse modo, diversas ações foram realizadas pelos mesmos no sentido de levar o debate da saúde do trabalhador ao maior número possível de pessoas em seus ambientes de trabalho. 
A criação de tal estratégia partiu do pressuposto de que trabalho e formação são indissociáveis; implicou no delineamento de ações para que os canais de comunicação fossem ampliados nos espaços das escolas participantes do projeto piloto. Essa ampliação contemplou o estabelecimento e/ou fortalecimento de parceria com outros equipamentos sociais, bem como o envolvimento de todos os sujeitos que compõem a comunidade escolar: trabalhadores, alunos e familiares.

Há que se considerar ainda que esse empreendimento está inserido no processo de construção, e consolidação de um espaço público, compreendido aqui como espaço da deliberação conjunta. Conforme destaca Innerarity (2006, p. 107) "o espaço público é o espaço cívico do bem comum, por contraposição ao espaço privado dos interesses particulares". Para Arendt (2002), a política tem a ver com o "viver juntos"; surge não no homem, mas entre os homens, pois exige uma sociabilidade política referendada pela ação e pelo discurso de cada um. A política surge no intraespaço e se estabelece como relação. Daí porque a política não é da natureza do humano, mas do agir humano, portanto, é uma forma de viver juntos e não a forma de viver juntos, pois o que constitui a realidade é a copresença no mundo, uma comunidade de sentido, cujo espaço público é mediatizado pela palavra, pelas opiniões e razões de cada um. Portanto, se a saúde ${ }^{6}$ é uma questão política, ela diz respeito à vida comum, diz respeito a todos nós.

Nesse sentido, a concepção de formação adotada pelo COSATE não priorizou o processo de ensino e aprendizagem de conteúdos conceituais a serem aplicados ao meio de trabalho em sua perspectiva utilitarista, mas voltou-se à criação de formas de convivência e de interação como um modo de compartilhar juntos a responsabilidade pelo mundo comum em torno da saúde dos trabalhadores da educação. Mundo esse entendido como "uma comunidade de coisas que reúne os homens e estabelece uma relação entre eles" (ARENDT, 2010, p. 76). Se o significado da vida pública está justamente em tornar legítima a participação de todos, à medida em que são capazes de ação e opinião, o processo formativo ensejado implicou em uma escuta sensível e no fortalecimento de trocas culturais, tendo em vista à consolidação de uma experiência na qual as questões da saúde como um direito dizem respeito a um destino comum de todos os professores e não à esfera privada de cada

\footnotetext{
6 Não entraremos com mais detalhes aqui na complexa discussão acerca da noção de saúde, mas faz-se necessário afirmar que a tomamos sob uma perspectiva que não a reduz ao plano orgânico, o qual remete à manutenção de um equilíbrio fisiológico, como acreditaram durante séculos e, de certo modo, até hoje, as ciências da saúde, em especial, a Medicina. Em oposição a essa ideia de equilíbrio, de enquadramento orgânico, bem como a designação frequente de saúde por ausência de doença, como negatividade, adotamos a perspectiva instituída por Canguilhem (1990) de saúde como capacidade normativa inerente à vida, como a capacidade de instituir novas normas em situações novas, o que extrapola medidas previamente definidas do que seja saudável ou patológico. Essa noção dá visibilidade ao mecanismo dinâmico da vida, a qual se modifica diante das adversidades.
} 
um, uma vez que a compreensão de política adotada não tem por referência o Estado e nem mesmo aos interesses privados, mas a capacidade humana de agir e deliberar em conjunto.

Frente a esse desafio, delineia-se a questão: é possível a construção de um mundo comum por meio de uma estratégia formativa? Como construir uma experiência pública em tempos nos quais a experiência mesma se encontra em crise?

\section{Ação política e experiência}

As contribuições arendtianas (CARVALHO, 2013; ALMEIDA, 2011; TELLES, 2006; ARENDT, 1997) sobre a crise da tradição e do pensamento, dos modos de julgar e de agir inaugurados na modernidade ${ }^{7}$, indicam como a desresponsabilização pelo mundo constitui verdadeira crise da liberdade e do sentido de público. E nesta perspectiva, a banalidade do mal se forja numa sociedade em que a ação política encontra-se reduzida. Tal sociedade mostrase indiferente às questões públicas, tornando-se cada vez mais atomizada e individualista. Essa crise produz efeitos peculiares no âmbito da educação (ARENDT, 1997). Aquilo que não se torna compartilhável, compartilhado, audível e visível, perde-se da esfera do reconhecimento e da legitimidade conferida pela fruição da experiência comum. Pode-se cair nas malhas do esquecimento e produzir apagamento das diferenças reais, com o consequente efeito de riscos políticos agigantados para todos.

Em alguma medida, as construções do mundo comum ficam, diante deste panorama, fragilizadas e fronteiriças. As significações tecidas pelo compartilhamento das experiências se diluem e a pluralidade humana fica confinada aos interesses privados mais expressivos. Como bem demonstrou Arendt (1997), o fardo do século exige testemunho coletivo para ganhar sentido e para ser suportado e transformado.

Em sua abordagem acerca da condição humana, Arendt (2010) desloca a pergunta o que é o homem, para pensá-lo como coconstrução engendrada em

\footnotetext{
$7 \quad$ Arendt (1997) define a época moderna como a lógica inaugurada pelo advento da ciência, que se inaugura entre os séculos XVI e XVII e atestada pelo racionalismo cartesiano. Afirma a autora que esta época, ou este mundo moderno não surgiu de um súbito definhamento da fé em Deus, mas sua origem esteve ligada à perda de confiança na capacidade reveladora da verdade dos sentidos. Nas palavras da autora: "A época moderna começou quando o homem, com o auxílio do telescópio, voltou seus olhos corpóreos rumo ao universo, acerca do qual especulara durante longo tempo [...] e aprendeu que seus sentidos não eram adequados para o universo, que sua experiência quotidiana, longe de ser capaz de constituir o modelo para a recepção da verdade e aquisição de conhecimento, era uma constante fonte de erro e ilusão. Após essa decepção - cuja enormidade nos é difícil perceber, por ter ocorrido séculos antes de seu pleno impacto se ter feito sentir em toda parte e não apenas no meio um tanto restrito de sábios e filósofos -, as suspeitas começaram a assediar o homem moderno de todos os lados. Sua consequência mais imediata, porém, foi o espetacular ascenso da Ciência Natural, que por longo período pareceu liberar-se com a descoberta de que nossos sentidos, por si mesmos, não dizem a verdade" (ARENDT, 1997, p.85-86).
} 
condições históricas. Não existe o homem como um dado da natureza tão somente, embora possamos nos reconhecer como espécie (PETRY, 2012), mas sim, os homens. Tal exercício implica tomar o agir humano em sua pluralidade de manifestações, considerando as inúmeras possibilidades de composições singulares: "[...] a pluralidade é a condição humana porque somos todos iguais, isto é, humanos, de um modo tal que ninguém jamais é igual a qualquer outro que viveu, vive ou viverá" (ARENDT, 2010, p. 10).

Tendo isso em vista, a construção de uma política pública deve se efetuar no entre possível da pluralidade de que se constitui o humano e da negociação de uma medida para um mundo comum. Num exercício de articulação com as proposições de Innerarity (2006, p. 9) "só pensando o que devemos entender hoje por comum poderemos resolver o velho dilema entre a unidade e a diferença", delineia-se a questão: que comum não identitário pode ser afirmado num processo formativo de modo a sustentar uma política pública de fato?

Petry (2012) explica que, para Arendt, o comum não pode ser tomado como uma medida de igualização ou um elemento de identificação, mas como aquilo que pertence a todos. Trata-se de uma construção que só pode ser concretizada na comunicação entre as pessoas. Sob esse mesmo viés, Carvalho (2013, p. 78) afirma: “[...] A esfera pública surge a partir da constituição de um mundo comum, não no sentido de um espaço coletivo vital e natural, mas no de um artifício propriamente humano, que nos reúne na companhia dos outros homens e de suas obras".

Desse modo e a partir de tal raciocínio, as noções de igualdade e direito também não são auto evidentes. Direito e igualdade são referentes a pertencimentos. Petry (2012) destaca que para Arendt, a condição humana não é soma das capacidades totais humanas. $\mathrm{O}$ que o homem produziu, e não apenas no sentido da fabricação, mas também, de ação, produz o próprio homem. Assim, o que estaria em jogo na condição humana é a abertura para a coconstrução de outros mundos, e, em última instância, a criação de uma humanidade comprometida com a coprodução do comum. Para Arendt (2010, p. 8), "A ação, única atividade que ocorre diretamente entre os homens, sem a mediação das coisas ou da matéria, corresponde a condição humana da pluralidade, ao fato de que os homens, e não o Homem, vivem na Terra e habitam o mundo". A ação é assim, o que nos distingue como humanos e seu meio privilegiado é o espaço público, o qual se diferencia da esfera privada de vida no sentido de que a ação deve garantir o bem comum, enquanto os interesses privados estão restritos ao âmbito das necessidades individuais. Contudo, destaca Telles (2006, p. 47) em sua alusão à Arendt: 
Sua discussão não é travada no sentido de desqualificar a vida privada, mas de estabelecer o seu lugar e definir as fronteiras entre duas formas distintas de existência social, duas formas diferentes, poderíamos dizer, de se fazer a experiência em sociedade. São essas fronteiras que se diluíram no mundo moderno. E isso significa a perda dos critérios de diferenciação entre aquilo que tem como medida a vida de cada um e aquilo que tem o mundo como medida. Nesse caso, os homens tenderão a tomar sua própria subjetividade como referência exclusiva de verdade e julgamento. (TELLES, 2006, p. 47)

Petry (2012) aponta também que, para agir, é preciso o testemunho de outros indivíduos, reconhecimento do direito a ser visível e audível, do direito à pronúncia e diferenciação, afirmando que fora de um meio compartilhado não há política. Contudo, qual o estatuto da experiência que se está a requerer, com estas reflexões?

Conforme apontou Arendt (1997) e Benjamin (1992) os modos de vida da modernidade produziram o esfacelamento da tradição e a perda da autoridade do passado. Insurge um estado de impotência que solavanca e arrasta a todos. E se, no entanto, já não é possível acessar a tradição como um legado das heranças simbólicas e materiais seguro, o que fazer das vicissitudes que a modernidade engendrou? Essa inquietação, tanto em Benjamin, Agamben, como também em Arendt, não produz uma defesa conservadorista:

\footnotetext{
Tal atitude conservadora, em política - aceitando o mundo como ele é, procurando somente preservar o status quo -, não pode senão levar à destruição, visto que o mundo, tanto no todo como em parte, é irrevogavelmente fadado à ruína pelo tempo, a menos que existam seres humanos determinados a intervir, a alterar, a criar aquilo que é novo. (ARENDT, 1997, p. 242)
}

Tal inquietação pode ser apreendida em Benjamin (1992), quando o mesmo aponta que a narrativa vai tornando-se cada vez mais arcaica na sociedade moderna, em que se testemunha a morte do narrador. Ele considera que a decadência da narrativa liga-se ao advento do romance e da imprensa, acontecimentos que fazem surgir uma nova forma de comunicação: a informação. A partir daí, o autor chama-nos a atenção para o fato de sermos bombardeados cotidianamente, cada vez mais, com as informações: "Cada manhã somos informados sobre o que acontece em todo o mundo. E, no entanto, somos tão pobres em histórias maravilhosas!" (BENJAMIN, 1992, p. 34). Para ele, tratase de um processo de empobrecimento da experiência. 
Nesse ponto, faz-se necessário destacar que o conceito de experiência em Benjamin nos parece assumir diferentes nuances ao longo de sua obra. Se, em O Narrador Benjamin alerta para nossa pobreza de experiências, indicando a importância de uma partilha de intensidades impessoais que tecem os fios de uma cultura, em Experiência e pobreza (BENJAMIN, 2012) situa justamente essa pobreza como um plano possível para a construção de novas formas de estar no mundo. Neste ensaio ainda, Benjamin assinala, curiosamente, que se os documentos de cultura constituíram-se em documentos de barbárie, uma vez que evidenciam a história dos vencedores, por outro lado, mais ainda importar-nos-ia produzir uma inversão desses códigos e afirmar uma dimensão positiva da barbárie, no sentido de que bárbaro é aquele que abre novos caminhos com pouco. Tal proposição possibilita-nos pensar que as formas tradicionais de produção de sentido que denotam a experiência como "acúmulo de saber" ou "autoridade instituída" já não são mais possíveis; há uma experiência a ser forjada com este "pouco" que nos resta.

Parece que no campo do compartilhamento das experiências, um limite ainda se espraia: há algo que comparece nos movimentos de partilha do comum e que esbarra numa certa fratura do dizível, fratura dos regimes de significação. Alguma coisa que resta inenarrável e que, contudo, torna complexos tais processos, já que os mesmos não se dariam somente nos regimes de expressão e permaneceriam também numa zona intensiva. Como acessar esta potência? Na trilha aberta por essa questão, retomamos a história (campo da experiência) não somente como aquilo que se vê ou de que se fala. Compartilhar experiências suscita lidar com os diversos significados inerentes à pluralidade humana e afirmar uma linha de porvir, certa indiscernibilidade de intensidade potencial. Há algo que se presentifica diante da reunião dos homens e em suas partilhas: algo que escapa, transita, bifurca, desvia, bordeja, abre-se. Como bem diria Arendt (2002, p. 53) se a ação depende da pluralidade dos homens, na medida em que os homens podem agir "[...] são capazes de levar a cabo o improvável e o imprevisível e de levá-lo a cabo continuamente mesmo sem saber disso".

Narrar certa história das experiências humanas constitui um movimento de reconciliação com o mundo, como sugere Almeida (2011). Mas abrir-se para o que resta inenarrável é assumir a força daquilo que insiste em transmitir-se, contudo. E que pode produzir diferença no modo como nos organizamos na contemporaneidade.

Não seria essa a possibilidade de uma barbárie positivada: a de se poder fazer algo com as ruínas e com os cacos? Seria essa uma articulação com o tempo oportuno, tal como proposto por Agamben (2005)? 
"Cada instante é a porta estreita pela qual o messias pode passar" (BENJAMIN, 1992, p. 70). Retomando a afirmação benjaminiana do tempo messiânico, de uma história feita a partir da ruína e afirmada a contrapelo, como uma nova forma de experiência e temporalidade, Agamben (2005) aponta que a recusa de uma experiência manipulada e guiada como em um labirinto de ratos, pode ser provisoriamente uma defesa legítima. Nesse sentido, criticando a pretensão cientificista que tenta impor-se no lugar da tradição, o autor considera que nossa incapacidade de fazer e transmitir experiências nem é mais um dado da catástrofe como realizada pelas guerras mundiais no contexto de Benjamin. O homem moderno diante de sua pacífica existência cotidiana, entre a "mixórdia de eventos - divertidos, maçantes, banais ou insólitos, agradáveis ou atrozes" (AGAMBEN, 2005, p. 22) que lhe sucedem, volta extenuado para sua vida.

Retomando a noção de autoridade, presente em Arendt e em Benjamin, Agamben (2005) indica que a experiência outrora passava pela palavra e pelo conto, tecida por uma comunidade de ouvintes e publicizada de forma compartilhável. Isto produzia uma apropriação da banalidade do cotidiano e sua transformação em pérola a ser transmitida, recontada.

Porém, "o que caracteriza o tempo presente é que toda autoridade tem o seu fundamento no 'inexperenciável', e ninguém admitiria aceita como válida uma autoridade cujo único título de legitimação fosse uma experiência" (AGAMBEN, 2005, p. 23). Ainda assim, o autor afirma que isto não significa que hoje não existam mais experiências. Mas que estas se efetuam fora do homem e, que curiosamente, o homem olha para isso com certo alívio.

$\mathrm{O}$ que estaria em pauta nesta nova possibilidade de experiência? Um giro possível: a da construção de outra temporalidade. O instante é a história, afirma o autor. Seguindo as pistas do intempestivo, como a própria definição do contemporâneo, Agambem (2009) propõe uma aposta no tempo que resta. Um tempo que guarda em sua presentificação a possibilidade de um devir histórico, ou seja, uma história que é um não cessar de acontecer.

Assim, teríamos que, segundo Agamben (2007), tornar possível a profanação. Profanar apontaria para novos usos do que nos resta. Profanar o sagrado passa por retornar ao uso comum àquilo que foi sacralizado, libertando a história da única versão, da Verdade.

Isso se coloca como uma tarefa para o pensamento: tocar nos possíveis em duas direções: uma, que abarque o ponto de vista histórico, filosófico e estético e outra, que se desdobre na problematização de uma perspectiva ética. A história é um limiar que não se pode atravessar plenamente, mas que se constitui somente como travessia. 


\section{A formação como dispositivo a ser profanado: uma aposta na amizade}

Retomar o processo formativo que empreendemos com o projeto piloto das COSATEs constitui-se, desta maneira, em um interessante exercício para pensar as indagações e desafios propostos por Agamben (2009): se toda forma de política está se transformando em máquina governamental, como produzir uma nova política por meio da amizade que propicie também outro modo de se relacionar com o tempo e que demande compartilhamento da existência? E, partindo por esta via, como não deixar-se capturar pelos mecanismos gestionais produtivos (dispositivos) que, na atualidade, têm sinalizado que toda política caminha para a catástrofe?

Agambem (2009) apresenta e amplia o conceito de dispositivo em Foucault, apontando o sujeito como aquele que resulta da relação entre os viventes e os dispositivos. Para o autor, estes estariam presentes em todas as relações em nosso modo de vida capitalista contemporâneo. Assim, dispositivo seria: "[...] qualquer coisa que tenha de algum modo a capacidade de capturar, orientar, determinar, interceptar, modular, controlar e assegurar os gestos, as condutas, as opiniões e os discursos dos seres viventes" (AGAMBEN, 2009, p. 40).

Nesta perspectiva, os modos de vida e os processos de subjetivação tecidos na atual conjuntura capitalista instauram uma indiferenciação entre subjetivação e dessubjetivação, desta situação emergindo então o sujeito espectral, fugidio, deslizante, que não se firma e, portanto, não se torna real, concreto.

Neste cenário, a tragédia para qual se encaminha a política a que Agamben (2009) se refere é o fato dela "girar no vazio", efeito da dessubjetivação e subjetivação dos sujeitos espectrais, que não se configuram como sujeitos reais e que, portanto, dificultam a ação política e a produção de diferenças, visto serem homogeneizados. Tal qual uma superfície lisa, perfeitamente homogênea, deslizante, o sujeito espectral não oferece resistência, não marca seu lugar, não cria alteridade.

Essa ideia é paradoxal porque ao mesmo tempo em que os dispositivos modernos produzem o que Agamben (2009) chama de "processos de indiferenciação entre subjetivação e dessubjetivação", tal mecanismo acaba por lançar mão de mais e mais dispositivos para capturar este sujeito espectral que não toma forma, desvanece com rapidez. Sem o sujeito real e a produção de diferença, não há uma política que se constitua no entre da pluralidade humana - numa articulação com Arendt (2009) -, uma vez que o sujeito deslizante e espectral não produz este espaço, ou um agio:

O termo agio indica de facto, de acordo com o seu étimo, o espaço ao lado (ad-jacens, adjacentia), o lugar vazio em que cada 
um se pode mover livremente, numa constelação semântica em que a proximidade espacial confina com o tempo oportuno (ad -agio, ter agio) e a comodidade com a justa relação. (AGAMBEN, 1993, p. 27)

Nas escolas operam os mais diversos dispositivos de poder ao qual o autor se refere: a hierarquia, o quadro e o giz, a disposição das carteiras; a economia dos mecanismos de controle do trabalho - pauta, horário das aulas, distribuição das turmas -, num modo institucionalizado de formação, nas regras de relacionamento estabelecidas entre diferentes segmentos, entre outros. Tais dispositivos se inserem numa lógica de docilização do trabalhador da educação - um corpo eficiente que não falte, não adoeça, não questione.

Muitos dos diversos tipos de comissões que hoje funcionam nas escolas do Ensino Básico também podem se constituir (e tem se constituído) em mais mecanismos de coerção, principalmente quando sua função, desviada da oportunidade de uma participação ampliada da comunidade escolar, tornam-nas tão somente mecanismos de validação de um modo de gerir que já vem pronto de cima para baixo, restando aos participantes tão somente validar, dizerem $\operatorname{sim}$ (LACAZ et al., 2012).

As COSATEs nas escolas podem também cair nesta função normatizadora? Sim, na medida em que não servirem como oportunidade para o trabalhador colocar em análise a organização do trabalho e a partir disso criar estratégias de ação que validem os modos de atuação impostos. Nesse funcionamento, restringir-se-iam as possibilidades de gestão do trabalho desses profissionais e de construção de um espaço, um entre onde se daria a política (ARENDT, 2009). Restringir-se-ia a possibilidade de produzir novas normas em meio ao inesperado das condições de trabalho (SCHWARTZ; DURRIVE, 2007; 2015). Na medida em que estas Comissões não produzam permanentemente a possibilidade de recriar novas formas de trabalhar e de viver (SILVA; BARROS; LOUZADA, 2011; CLOT, 2008), correm o risco de tornar-se mecanismo de contenção, de aprisionamento e de diminuição da potência de vida.

Quando Agamben (2009) apresenta a noção de dispositivo, apresenta também dois outros conceitos que o contrariam, que possibilitam um caminho de ação política localizada fora da esfera governamental. São as noções de profanação e de amizade.

Enquanto o dispositivo advém de rituais de sacralização, ou seja, de retirar algo que era do uso comum no mundo dos homens e torná-lo por meio de ritos e sacrifício em algo de uso restrito aos deuses tornando este objeto sagrado, profanar seria o ato de restituir aos homens o uso deste objeto. Esta ideia de sagrado, rito e sacrifício compõe a preocupante constatação que Agamben 
(2007), a partir dos textos benjaminianos lança: o capitalismo é a religião moderna e, como tal, opera com seus ritos e mitos, sacralizando e, portanto, privando o homem do uso comum destes objetos agora sagrados. Profano então é algo que inicialmente existia para uso dos homens e por meio de rituais e sacrifício foi sacralizado para mais tarde, também por meio de rituais, ser devolvido ao uso dos homens. Estabelece, todavia, diferença entre profanação e secularização. Enquanto essa última opera mantendo intacto o poder e seu exercício por meio de outros mecanismos, embora restituído ao uso dos homens; a profanação seria a perda da aura sagrada, a desativação de todos os dispositivos de poder.

A ideia de profanação de Agamben (2007) pode ser articulada à de ação política proposta por Arendt (2009), uma vez que ambas são perpassadas pela noção de liberdade, de criação, de se fazer um novo uso de algo, bem como de ação que se realiza em comum. Ou ainda, profanar é fazer livre uso das coisas, sem delas tomar posse ou direito. E ação política implica a não funcionalização da ação. Nesse sentido, profanar é realizar uma ação política. Implica em contato, em exercício de liberdade e também em fazer frente aos dispositivos de poder e da ação humana como efeito deste poder.

As COSATEs, tal como preconizadas dialogicamente pelos membros do Fórum, apostam na constituição de possibilidades de suspensão de certos dispositivos e pode-se dizer que sob tal viés; apostam na profanação.

Se a ideia de profanação defendida por Agamben (2007) implica num exercício de liberdade frente aos mecanismos de poder e também em desestatização da ação, a implementação das COSATEs e a negociação com diretores e SEDU/Serra situá-las-iam no âmbito da secularização ao invés do da profanação?

A aposta de que as COSATEs constituam possibilidade de profanação reside muito mais no fato delas empreenderem e dispararem uma ação comum (tendo como eixo a produção de saúde) do que no fato de ser ela mesma uma forma institucionalizada. A profanação não é algo que se possa planejar ou garantir. Ela é a atualização do imprevisível, de abertura, de milagre, diríamos com Arendt (1997).

Os mínimos deslocamentos produzidos durante o projeto piloto, as renormalizações efetivadas (SCHWARTZ; DURRIVE, 2007) pelos participantes em seus cotidianos na escola, em sala de aula, com os demais trabalhadores, dialogando e analisando seus processos de trabalho, permitem valermo-nos da formação das COSATEs apostando em sua potência.

Por exemplo, à medida que tais Comissões identificam problemas no meio de trabalho - como na relação precarizada com os trabalhadores terceirizados; 
dificuldades de ordem estrutural e física; ou a realização de reformas e construções nas escolas não pactuadas previamente junto à comunidade escolar, gerando transtornos aos trabalhadores e alunos - e, por meio de conversas, embates e consensos, desencadeiam soluções locais para os mesmos; delineiam outro modo de gestão das atividades nas escolas. A criação de canais de conversa e sustentação do pensar e agir em comum pode comportar novas formas de participação não instituídas e derivar ações de profanação. Já que profanar seria "[...] pensar e promover o avesso da vida nua, a potência da vida e a vida humana como potência de ser e de não ser" (AGAMBEN, 2007, p. 9).

$\mathrm{Se}$, como colocado anteriormente, o capitalismo configura-se como a religião moderna, seus efeitos não vêm redimir os pecados dos trabalhadores, mas perpetuam e ampliam a produção da culpabilização individual pelos impasses produzidos no meio de trabalho (AGAMBEN, 2007). Nesta lógica, se o indivíduo adoece em função do desempenho de suas atividades profissionais, uma explicação recorrente é a de que ele é mais frágil ou não se cuida; não sendo discutidos os efeitos de inúmeras determinações que se colocam no campo da educação. Reafirmamos: o trabalho não pode ser analisado de maneira isolada, com foco exclusivo no trabalhador, culpabilizando-o, é preciso incluir diversos fatores que constituem o exercício da atividade docente.

Ao questionarem e proporem novos modos de organização do trabalho, as COSATEs profanam: aventuram-se, lançam-se, puxam pelas ventas o prazer da empreitada, agem, realizam um exercício de liberdade. As COSATEs, como esse jogo, podem se constituir como mecanismo que é:

\begin{abstract}
[...] puro meio, ou seja, uma prática que, embora conserve tenazmente a sua natureza de meio, se emancipou de sua relação com uma finalidade, esqueceu alegremente seu objetivo, podendo agora exibir-se como tal, como meio sem fim. Assim a criação de um novo uso só é possível ao homem se ele desativar o velho uso, tornando-o inoperante. (AGAMBEN, 2007, p. 74-75)
\end{abstract}

Então, mais do que simplesmente superar a separação, profanar envolve fazer novo uso de um modo organizativo, a saber, o modo "comissão", jogar com ele. E isso só pode ser feito de modo coletivo e também entendendo o jogo como episódio, contradispositivo ${ }^{8}$ passageiro, pois sempre há novos modos de captura, de sacralização (AGAMBEN, 2009).

$\mathrm{O}$ outro modo de desmontar os dispositivos de poder proposto pelo autor italiano é através do exercício da amizade, que implica proximidade (não necessariamente espacial). Ser amigo é estar próximo, daí sua convocação

Para Agamben (2009) contradispositivo pode ser lido como sinônimo de profanação. 
política: não é possível fazê-la estando distante. Para falar da ação política implícita no gesto da amizade, Agamben (2009) recorre a Aristóteles e postula: conviver é diferente de condividir. Conviver é mais do estar no mesmo espaço, conviver é "com-sentir", sentir junto.

Conviver, nesse sentido, refere-se a uma partilha de vidas que, apesar de diferentes, ou justamente por isso, são constituídas nestes encontros, no "com". Daí outro entrelaçamento possível com a noção de ação política de que nos fala Arendt (2009): a amizade, que também implica na arte de ver o mundo pelos olhos do outro, é uma "percepção política por excelência". Assim, é possível falar da noção de amizade como liberdade que tem dimensão consensual, de conversa, de proximidade.

Lançar-se ao desafio em uma COSATE oportuniza, então, um meio para criar, para inventar, brincar com dispositivos de poder que sacralizam a gestão do trabalho. Porém, isso requer estar em relação, produzir consenso, com-sentir:

\begin{abstract}
Em termos modernos se poderia dizer que "amigo" é um existencial e não um categorial. Mas esse existencial - como tal, não-conceitualizável - é atravessado, entretanto, por uma intensidade que o carrega de algo como uma potência política. Essa intensidade é o syn, o "com" que divide, dissemina e torna condivisível - ou melhor, já sempre condividida - a sensação mesma, a doçura de existir. [...] E é essa partilha sem objeto, esse com-sentir originário que constitui a política. (AGAMBEN, 2009, p. 91-92)
\end{abstract}

Neste sentido, articulando essa noção de compartilhamento com a ideia de amizade em Arendt (2009), que não pode ser reduzida à intimidade, vislumbra-se um modo de pensar a vocação humana de se associar aos outros por meio do diálogo que se realiza no espaço do entre, apontando assim na amizade como requisito para pensar, julgar e agir.

Orientar a atividade das COSATEs na direção da amizade implica então na capacidade de dialogar com todos os profissionais que trabalham na escola, ouvindo, compondo com eles, agindo para pôr uma dada organização do trabalho em suspensão para forjar novos possíveis, compartilhar experiências, problemas e criar, em conjunto, estratégias e caminhos de ação.

Isolada, com meios frágeis de comunicação e envolvimento com a comunidade escolar, é provável que iniciativas como esta funcionem de forma institucionalizada e engessada, dificultando a desmontagem dos dispositivos de poder. Por outro lado, ao funcionar como contradispositivo, a formação propiciada pela experiência do Projeto Piloto das COSATEs resultou em intervenções partindo de uma analítica coletiva sobre o ambiente de trabalho, envolvendo os 
profissionais da escola e a equipe em formação e os demais potenciais parceiros de uma rede aquecida pelo próprio trabalho das COSATEs. É a tecitura de uma política no sentido afirmado neste texto, feita pelo e para o trabalhador da escola que engendra um novo modo de pensar a produção de saúde rompendo com os modelos institucionalizados. Isto constitui ações políticas de profanação, uma vez que funciona como coconstrução da elaboração de políticas e cuidados com a saúde do trabalhador. Como exercícios de contradispositivo são elaborados planos de ação, criação de instrumentos para pesquisa sobre situações de adoecimento no ambiente escolar, realização de um seminário sobre Saúde do Trabalhador para a Rede Municipal, inserção de temas relevantes para as garantias das condições de trabalho em espaços deliberados pela SEDU/Serra, entre outros.

Assim, o processo de formação empreendido com as COSATEs de Serra atentou-se para a sustentação nos modos de exercício da amizade visibilizados no trabalho, apostando nas possibilidades de profanação que o próprio cotidiano guarda.

Por fim, apostamos nessas Comissões como meio de materializar uma experiência de educação que possibilite ao trabalhador a potência da ação de uma política pública, produzindo modos mais autônomos de gestão do trabalho, abrindo chances de desmontagem dos mecanismos que capturam a ação humana.

\section{Considerações finais}

Esse é tempo de partido

Tempo de homens partidos.

Em vão percorremos volumes,

Viajamos e nos colorimos.

A hora pressentida esmigalha-se em pó na rua.

Os homens pedem carne. Fogo. Sapatos.

As leis não bastam. Os lírios não nascem da lei.

Meu nome é tumulto, e escreve-se na pedra.

(Carlos Drummond de Andrade)

O cotidiano é forjado por linhas, pelo tempo, por fazeres e saberes. Ele escapa e se apresenta como réstia, como ordinário, como astúcia. O cotidiano guarda chances para a experiência. 
Agamben (2005) mostrou como a existência cotidiana tem nos colocado certa "opressão" e banalidade (p. 22). Mas afirma também que o próprio cotidiano e não o extraordinário constitui matéria-prima daquilo que pode ser transmitido.

Retomando nossa questão inicial e tendo em vista as discussões brevemente esboçadas ao longo deste artigo, consideramos ser a experiência um conceito potente de articulação das várias linhas que se abrem em nossa prática de pesquisa-intervenção. Tal noção nos é cara em seu sentido de construção coletiva impessoal, forjada nas fraturas da história, assim como nos é também a narrativa, seu meio de transmissão. Nas conformações dos modos de vida atuais, em que se sobrepõe uma lógica individualizante, como já mencionado, o desafio que se coloca aos movimentos que intencionam a construção de uma política pública de fato, nesses termos, é o de criar um chão possível à produção dessa experiência, bem como a construção de uma narratividade que a permita germinar. Seria essa uma baliza maior na direção da qual podemos orientar nossas ações, visando à profanação dos dispositivos regulatórios hegemônicos.

Ao que essa perspectiva nos conduz tendo em vista o processo formativo que empreendemos junto às COSATEs? À aposta permanente na possibilidade da construção de um comum, sem garantias a priori; à tarefa de trazer a um plano de visibilidade as intensidades e os desvios, os movimentos que cindem o tempo, produzindo ranhuras num ordenamento colocado. A intencionalidade, nesse caso, não se coloca como garantia de algo.

O planejamento do espaço-tempo formativo, nesse sentido, ao priorizar os momentos dialógicos e o acolhimento às diferenças que emergem do campo configura-se apenas como uma aposta na possibilidade de efetuação de um arranjo coletivo pautado numa política da amizade; aposta na feitura de conjuga-ações, conexões. Assim, o que nos movimenta nessa empreitada é a convicção no movimento que se abre para um possível. Não se trata de alçar formas instituídas de ação, tão somente. Mas afirmar que enquanto se caminha, fazem-se caminhos. Pois, o milagre corre à espreita.

\section{Referências}

AGAMBEN, G. A comunidade que vem. Portugal: Editorial Presença, 1993.

AGAMBEN, G. Infância e História: a destruição da experiência e a origem da história. Belo Horizonte: Editora UFMG, 2005.

AGAMBEN, G. Profanações. São Paulo: Boitempo, 2007.

AGAMBEN, G. O que é o contemporâneo? E outros ensaios. Chapecó: Argos, 2009. 
AGUIAR, K. F.; ROCHA, M. L. Micropolítica e o Exercício da Pesquisa-intervenção: Referenciais e Dispositivos em Análise. In: Psicologia, Ciência e Profissão. v. 27, n. 4. p. 648-663, 2007.

ALMEIDA, V. S. Educação em Hannah Arendt: entre o mundo deserto e amor ao mundo. São Paulo: Cortez, 2011.

ARENDT, H. Entre o passado e o futuro. 4. ed. São Paulo: Perspectiva, 1997.

ARENDT, H. O que é política? Rio de Janeiro: Bertrand Brasil, 2002.

ARENDT, H. A promessa da política. 2. ed. Rio de Janeiro: DIFEL, 2009.

ARENDT, H. A condição humana. Rio de Janeiro: Forense Universitária, 2010.

BENDASSOLLI, P. F.; SOBOLL, L. A. P. (Orgs.). Clínicas do Trabalho: novas perspectivas para a compreensão do trabalho na atualidade. São Paulo: Atlas, 2011.

BENJAMIN, W. Sobre arte, técnica, linguagem e política. Lisboa: Antropos, 1992.

BENJAMIN, W. Magia e técnica, arte e política: ensaios sobre literatura e história da cultura. 8. ed. São Paulo: Brasiliense, 2012. (Obras escolhidas, v. 1).

BOTECHIA, F.; ATHAYDE, M. Conversas sobre o trabalho sob o ponto de vista da atividade: algumas abordagens metodológicas. In: BARROS, M. E. B.; HECKERT, A. L. C.; MARGOTO, L. (Orgs). Trabalho e saúde do professor: cartografias no percurso. Belo Horizonte: Autêntica, 2008. p. 43-70.

CANGUILHEM, G. O normal e o patológico. 3. ed. Rio de Janeiro: Forense Universitária, 1990.

CARVALHO, J. S. Reflexões sobre educação, formação e esfera pública. Porto Alegre: Penso, 2013.

CLOT, Y. A função psicológica do trabalho. Petrópolis, RJ: Vozes, 2006.

CLOT, Y. Travail et pouvoir d'agir. Paris: PUF, 2008.

FOUCAULT, M. Microfísica do Poder. 26. ed. Rio de Janeiro: Graal, 2008.

GUATTARI, F.; ROLNIK, S. Micropolítica: cartografias do desejo. 8. ed. Petrópolis, RJ: Vozes, 2007.

INNERARITY, D. O novo espaço público. Lisboa: Teorema, 2010.

LACAZ, A. S.; ROMANIO, M.; GOTARDO, S. M.; HECKERT, A. L. C. Questões contemporâneas no campo das políticas educacionais: produção comunitária, criminalização da vida e práticas de liberdade. In: Estudos e Pesquisas em Psicologia - UERJ. v. 12, n. 2, p. 479-500, 2012.

SILVA, C. O.; BARROS, M. E. B.; LOUZADA, A. P. F. Clínica da Atividade: dos conceitos às apropriações no Brasil. In: BENDASSOLLI, P. F.; SOBOLL, L. A. P. (Orgs.). Clínicas do 
Trabalho: novas perspectivas para compreensão do trabalho na atualidade. São Paulo: Atlas, 2011. p. 188-207.

SOUZA, A. S.; ALOQUIO, B. T.; FILHO, J. R.; CHIABAI, J. D.; LUCIANO, L. S.; BROTTO, T. C. A. As comissões e o núcleo de saúde dos trabalhadores: tateando "(re)-existências" da atividade docente. In: ROSEMBERG, D. S.; FILHO, J. R.; BARROS, M. E. B. (Orgs.). Trabalho docente e poder de agir: clínica da atividade, devires e análises. Vitória: EDUFES, 2011. p. 145-173.

PETRY, C. A ascensão da esfera social: a diluição da distinção entre público e privado. In: FÁVERO, A. A.; CASAGRANDA, E. A. (Orgs.). Leituras sobre Hannah Arendt: educação, filosofia e política. Campinas, SP: Mercado das Letras, 2012, p. 205-232.

SCHWARTZ, Y; DURRIVE, L. Trabalho e ergologia: conversas sobre a atividade humana. Niterói, RJ: Eduff, 2007.

SCHWARTZ, Y.; DURRIVE, L. Trabalho e ergonomia II: diálogos sobre atividade humana. Belo Horizonte: Fabrefactum, 2015.

TELLES, V. S. Direitos sociais: afinal do que se trata? Belo Horizonte: UFMG, 2006.

ZAMBONI, J.; SZPILMAN, A. R. M.; MIRANDA, G. U.; BARROS, M. E. B. Primeiras notas sobre o Fórum das Comissões de Saúde do Trabalhador da Educação (COSATEs) no Município de Serra, Espírito Santo. Advir, Rio de Janeiro, v. 30, n. 6, p. 105-118, 2013.

Submissão: $21 / 12 / 2015$

Revisão: $31 / 10 / 2016$

Aceite: 03/11/2016

Suzana Maria Gotardo é psicóloga do Instituto Federal do Espírito Santo (IFES), Doutoranda do Programa de Pós-graduação em Educação da Universidade Federal do Espírito Santo (PPGE/UFES) e pesquisadora do Núcleo de Estudos em Subjetividade e Políticas (NEPESP). E-mail: sugotardo@yahoo.com.br

Hervacy Brito é comunicóloga, doutoranda do Programa de Pós-graduação em Educação da Universidade Federal do Espírito Santo (PPGE/UFES) e pesquisadora do Núcleo de Estudos em Subjetividade e Políticas (NEPESP). E-mail: hervacy@hotmail.com

Maria Carolina de Andrade Freitas é psicóloga, doutoranda do Programa de Pósgraduação em Educação da Universidade Federal do Espírito Santo (PPGE/UFES), pesquisadora do Núcleo de Estudos em Subjetividade e Políticas (NEPESP) e professora do curso de Psicologia da Universidade de Vila Velha (UVV).

E-mail: mariacarol.andrade@gmail.com 
Maria Elizabeth Barros de Barros é professora do Programa de Pós-graduação em Educação da Universidade Federal do Espírito Santo (PPGE/UFES) e pesquisadora do Núcleo de Estudos em Subjetividade e Políticas (NEPESP). E-mail: betebarros@uol.com.br

Vânia Carvalho de Araújo é professora do Programa de Pós-graduação em Educação da Universidade Federal do Espírito Santo (PPGE/UFES) e Coordenadora do Grupo de Pesquisa Infância, Educação, Sociedade e Cultura (IESP). E-mail: vcaraujoufes@gmail.com 